\title{
Analysis of the regeneration behavior of high temperature polymer electrolyte membrane fuel cells after hydrogen starvation
}

\author{
Khrystyna Yezerska ${ }^{1,2, \star}$, Fang Liu ${ }^{1}$, Anastasia Dushina ${ }^{1}$, Oleg Sergeev ${ }^{1}$, Peter \\ Wagner $^{1}$, Alexander Dyck ${ }^{1}$, Michael Wark ${ }^{2}$ \\ ${ }^{1}$ DLR Institute of Networked Energy Systems, 26129 Oldenburg, Germany \\ ${ }^{2}$ Institute of Chemistry, Carl von Ossietzky University, 26129 Oldenburg, Germany \\ *Corresponding author, email: khrystyna.yezerska@dlr.de Tel.: +49 44199906346
}

\begin{abstract}
Two high temperature polymer exchange membrane fuel cells (HT-PEM FCs) were operated under repeated starvation/regeneration steps for 550 min (DPS-1) and 12 days (DPS-2). Concerning the investigation of the irreversible degradation under fuel $\left(\mathrm{H}_{2}\right)$ starvation the focus was put on the electrochemical characteristics during regeneration, since during this step the system operates under normal conditions. Electrochemical impedance spectroscopy (EIS) and distribution of relaxation times (DRT) analysis were used as electrochemical characterization methods. DRT analysis of selected impedance spectra during regeneration steps for the first seven days revealed an intensity increase of the charge transfer kinetics of the cathode (ca. $10 \mathrm{~Hz}$ ) and the anode (ca. $100 \mathrm{~Hz}$ ). From day 3 on, an additional peak at $300-800 \mathrm{~Hz}$ appeared likely pointing to the formation of surface oxides at the anode side. The EIS and DRT results were verified with Focused Ion Beam Scanning Electron Microscopy (FIB-SEM), Microcomputed Tomography $(\mu-\mathrm{CT})$ and Transmission Electron Microscopy (TEM). While TEM indicated advanced Pt particle agglomeration pointing
\end{abstract}


to carbon corrosion, $\mu$-CT measurements showed an increase of void volume fraction and a decrease of the tortuosity value. The combined results show that the anode gas outlet region of the $\mathrm{FC}$ is more degraded than the inlet region.

Key words: HT-PEM FC, starvation, regeneration, EIS, DRT, carbon corrosion

\section{Introduction}

High temperature polymer exchange membrane fuel cells (HT-PEM FC) are promising and environmentally friendly power sources, with the great opportunity to replace diesel generator sets for backup power applications, heat and gas engines and boilers for micro combined heat and power applications (Micro-CHP) and other devices [1]. A key performance factor for each power source device is durability. The target according to e.g. the U.S. Department of Energy is to reach the durability of 80.000 hours by 2020 (current status, 2018 40.000-80.000 hours (depending on FC type) [2]. However, a further increase in durability requires a better characterization and understanding of the degradation mechanisms which typically occur in HT-PEM FCs, allowing conclusions leading to improved components. One well known cause for degradation is fuel $\left(\mathrm{H}_{2}\right)$ starvation, which is the topic of this contribution, and which may occur due to internal and external factors such as e.g. channel blocking and start/stop operation, respectively [3].

The HT-PEM FC membrane electrode assembly (MEA) principally consists of two gas diffusion electrodes (GDEs) which are separated between each other by the polybenzimidazole (PBI-) based membrane with phosphoric acid as an ionic conductor. Each of the GDEs consists of gas diffusion layers (GDLs), micro porous 
layers (MPLs) and catalysts layers (CLs). GDLs and MPLs allow transport of the reactants (hydrogen and air/oxygen) from flow field channels to active sites of the CL. The latter consists of platinum (Pt) particles, catalyst carbon support and binder (perfluorinated sulfonic acid ionomer). Within the CL the electrochemical reactions occur, such as hydrogen oxidation reaction (HOR) on the anode side (Eq. 1) and oxygen reduction reaction (ORR) on the cathode side (Eq. 2).

$H_{2} \rightarrow 2 H^{+}+2 e^{-}$

$\mathrm{O}_{2}+4 \mathrm{H}^{+}+4 e^{-} \rightarrow 2 \mathrm{H}_{2} \mathrm{O}$

There are many consequences of $\mathrm{H}_{2}$ starvation on the HT-PEM FC. According to [4, 5] the degradation due to $\mathrm{H}_{2}$ starvation affects anode and cathode $\mathrm{CL}$ structures [6]. Further, in our previous paper [7] the starvation process was discussed in detail: the $\mathrm{H}_{2}$ undersupply leads to low $\mathrm{H}_{2}$ partial pressure against ambient pressure. The voltage of anode half-cell $\left(E_{a n}\right)$ increases to the cathode half-cell voltage $\left(E_{c a}\right)$ [8]. When the $E_{a n}$ becomes higher than the $E_{c a}[9]$ the overall cell voltage $\left(E_{c e l l}\right)$ reverses (Eq. 3) $[10,11]$.

$E_{c e l l}=E_{c a}-E_{a n}<0 \mathrm{~V}$

Under further FC operation $E_{a n}$ becomes sufficiently high for the oxygen evolution reaction (OER) i.e., water electrolysis. During $\mathrm{H}_{2}$ starvation unwanted air may penetrate into the anode side of the assembly from the open outlet and may build-up the combination of $\mathrm{H}_{2}$ and air (air front). The further $\mathrm{E}_{\mathrm{an}}$ increase leads to carbon oxidation reaction (COR) (Eq. 4) [4, 6, 12-17]. COR and OER are favorable reactions; COR thermodynamically and OER kinetically. The kinetically slow COR becomes faster at high voltages (i.e., $>1 \mathrm{~V}$ ).

$\mathrm{C}+2 \mathrm{H}_{2} \mathrm{O} \rightarrow \mathrm{CO}_{2}+4 \mathrm{H}^{+}+4 e^{-}$ 
Typically, COR leads to performance loss due to a reduction in the active surface area [4], a thinning and crack formation of the CL which may cause an increase in void volume. The $\mathrm{CL}$ thinning may lead to Pt particle detachment due to corrosion of the carbon support and their re-deposition onto particles that are still attached leading to $\mathrm{Pt}$ particle agglomeration, increase on particle sizes/particle size distribution $[5,18]$ and alteration of pore morphology and surface characteristics [4].

In our previous paper [7] two HT-PEM FC (DPS-1 and DPS-2) were cycled under repeated $\mathrm{H}_{2}$ starvation and regeneration steps over one day. During regeneration the FC was operated under normal conditions. The results showed that during starvation cell voltage over the active area of the FC significantly dropped from 0.6 to $0.1 \mathrm{~V}$ and the local current density reached much higher values (up to $0.3 \mathrm{~A} \cdot$ point $^{-1}$ ) at the $\mathrm{FC}$ area near the gas inlet $\left(9 \mathrm{~cm}^{2}\right)$ compared to much lower current densities at the FC area near the gas outlet $\left(0.01 \mathrm{~A} \cdot\right.$ point $\left.^{-1}\right)$. Since the current density distribution is directly dependent to the gas content during operation, the $\mathrm{H}_{2}$ content is higher at inlet than at outlet. The FC response during the subsequent regeneration steps was immediate, stable and constant, indicating that all degradation, which occurred during starvation, was reversible.

Further, the thicknesses of both cathode and anode CLs were reduced by about $30 \%$ [7]. Even if the CL thickness appeared to be reduced the performance of DPS-1 remained unchanged as seen during regeneration. Almost no difference between the thicknesses at inlet and outlet area of the same CLs was observed. It is likely that such starvation/regeneration routine during one day was too short to visualize significant differences on the area of $C L$ in two different regions. Therefore, the routine was now extended for DPS-2 to $\sim 12$ days as shown in this work. Due to the 
identical behavior of both MEAs during one day it can be assumed that the results for further days for those FCs can be comparable.

The focus in the present work is on the electrochemical characteristics notably during regeneration since (i) the FCs are expected to operate under stable conditions, and (ii) any irreversible degradation can only be noticed then. This serves for a more quantitative evaluation of the degradation influences from $\mathrm{H}_{2}$ starvation.

Electrochemical impedance spectroscopy (EIS) is a suitable nondestructive in-situ technique which analyzes polarization behavior with individual time constants [19, 20]. Typically, those polarization processes can be attributed to specific frequency ranges which are typical for the underlying electrochemical processes. Among those are ohmic resistivity at frequency range $>100 \mathrm{~Hz}$, charge transfer kinetics of the anode (high frequency range $>100 \mathrm{~Hz}$ ) and cathode (intermediate frequency range $10-100 \mathrm{~Hz}$ ) as well as mass transport (low frequency range $<1 \mathrm{~Hz}$ ) [3, 21-23].

Generally, the EIS response is analyzed by a complex nonlinear least square fit (CNLS) approximation to an equivalent circuit model (ECM) function [19]. However, such analysis has some disadvantages such as difficult differentiation between two polarization processes with similar time constants. Therefore, pre-identification of the EIS response aided by the distribution of relaxation times (DRT) analysis is useful [22]. In this work, DRT analysis is applied to the EIS response of a HT-PEM FC. The polarization processes under different frequencies are discussed. Further, the results from anode part of EIS (anode charge transfer kinetics) response will be verified with three different post-mortem imaging methods, such as Focused lon Beam-Scanning Electron Microscopy (FIB-SEM) [24], Microcomputed Tomography $(\mu-\mathrm{CT})$ and Transmission Electron Microscopy (TEM). Commonly, FIB-SEM and $\mu$-CT tomography are used to capture microscopic structures [25, 26]. Tomographic data 
are typically processed and stored as cuboid voxels (volume pixels), initially containing grey-scale image data, which can be converted into discrete regions using segmentation algorithms, which are increasingly based around machine learning techniques [27]. Both tomography methods may be used to visualize thinning and corrosion of catalyst layers [6] while TEM is useful to detect catalyst Pt particle size changes, mitigation and agglomeration [28].

As mentioned above increased crack formation within the CL may lead to increased void volume fraction. Therefore $3 \mathrm{D}$ microscopic volume is examined for volume fraction changes, from which tortuosity values are calculated [29, 30]. The tortuosity value is defined as the effective (or actual) length $\left(L_{e}\right)$ of the path of flow passing through a unit length $(L)$ of a medium and is depicted in Eq. 5. Thus $L_{e}$ is always $>L$. According to [31, 32] tortuosity is inversely proportional to the void volume or porosity of the material.

Tortuosity $=\frac{L_{e}}{L}$

\section{Experimental}

\subsection{Cell assembly}

Two commercial Dapozol ${ }^{\circledR}$ G77 (Danish Power Systems ${ }^{\circledR}$ ) FCs with an active area of $21 \mathrm{~cm}^{2}$ were used for the measurements. The FC with a thickness of around $0.6 \mathrm{~mm}$ was inserted between two graphite flow fields as outlined in [7].

\subsection{Electrochemical measurement techniques}

The electrochemical measurements were performed on a FuelCon AG (Evaluator-C 70316) test station. Prior to this the assembled HT-PEM FC was activated by heating 
up the cell under $\mathrm{N}_{2}$ supply to a temperature of $120^{\circ} \mathrm{C}$ [33]. After that reactant gases such as $\mathrm{H}_{2}$ were fed as fuel with a stoichiometric factor $\lambda_{A}=1.5$ for the anode and $\mathrm{O}_{2}$ with a stoichiometric factor $\lambda_{C}=9.5$ for the cathode as oxidant while the temperature was increased to $160^{\circ} \mathrm{C}$. Shortly, the load current was increased stepwise to 0.3 $\mathrm{A} / \mathrm{cm}^{2}$. The oversupply of oxygen prevents any influences from the cathodic side of the FC and for clear separation of degradation phenomena on the anode side $[7,22]$.

Both cells were activated until stable operation was reached at $0.3 \mathrm{~A} / \mathrm{cm}^{2}$ (with $\lambda_{A}=$ 1.5 and $\left.\lambda_{C}=9.5\right)$ and held for $168 \mathrm{~h}$ to reach homogeneous electrolyte distribution and stable output voltage. The starvation/regeneration cycles were repeated for a time period up to 8.000 minutes. Each cycle consisted of a starvation step with $\lambda_{A}=$ 1.0 at $0.3 \mathrm{~A} / \mathrm{cm}^{2}$ and subsequent regeneration step with $\lambda_{A}=1.5$ at $0.4 \mathrm{~A} / \mathrm{cm}^{2}$ for 20 minutes. $\lambda_{C}$ was kept at 9.5 under all conditions. The load of $0.3 \mathrm{~A} / \mathrm{cm}^{2}$ for the starvation step is a typical value for FC operation (e.g. [34]) while $0.4 \mathrm{~A} / \mathrm{cm}^{2}$ during regeneration assure full FC recovery after starvation.

\subsubsection{Electrochemical impedance spectroscopy (EIS)}

EIS data were collected with the potentiostat Ametek Solartron Metrology ${ }^{\circledR}$ in the frequency range of $10^{-1}$ to $10^{4} \mathrm{~Hz}$ and an $\mathrm{AC}$ amplitude of $10 \mathrm{mV}$ (galvanostatic mode) each minute during the 20 minutes of a regeneration step. The EIS spectra are classically shown as Nyquist plots as depicted in Fig. 1a where ohmic resistivity is indicated by the intercept of $Z_{\text {im }}=0$ [21] (Fig. 1a, blue). Figure 1a also shows charge transfer kinetics of the anode (red square) and cathode (green square). 


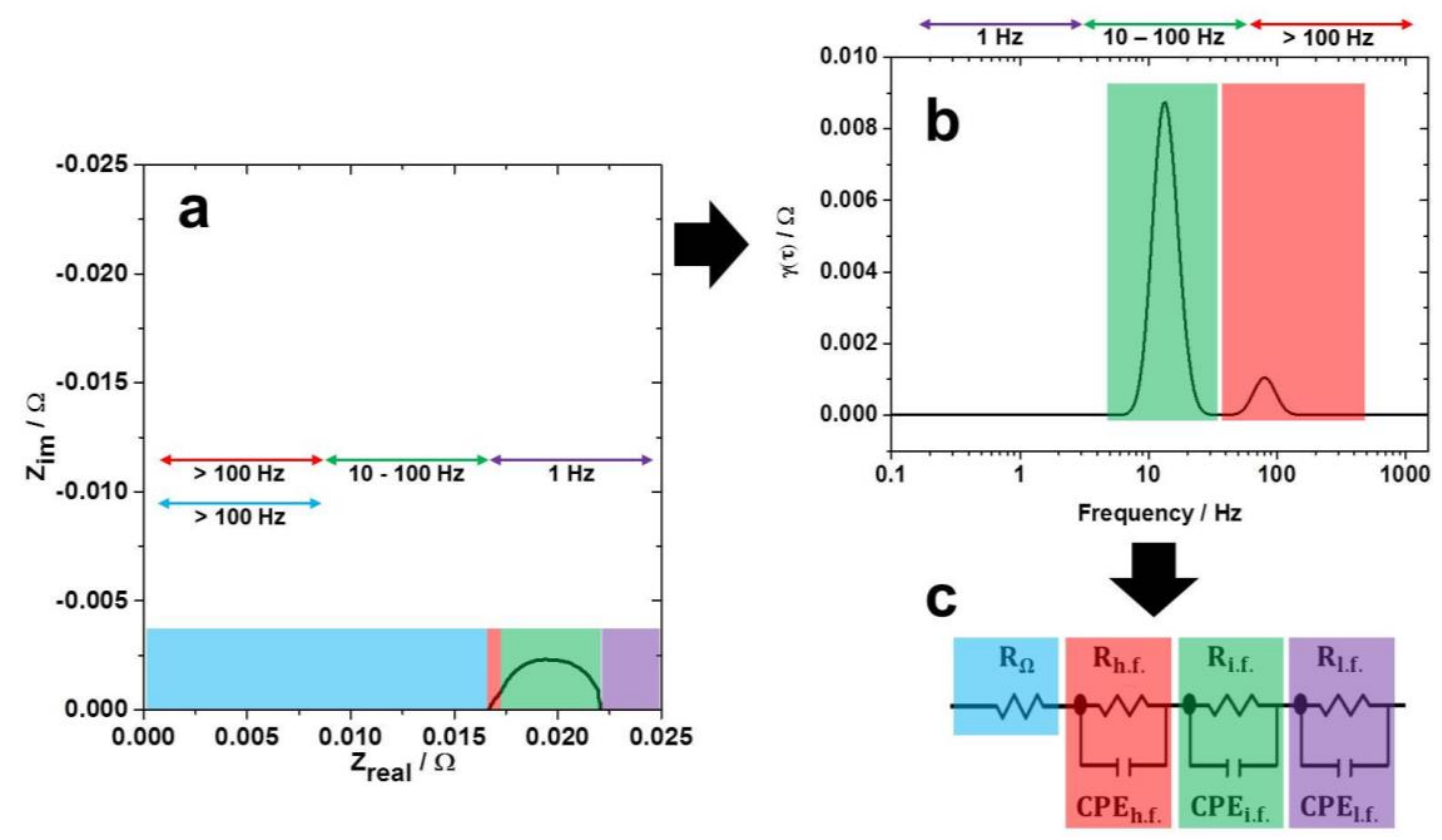

Fig. 1: Exemplary evaluation of EIS data: a) Nyquist plot; b) DRT plot; c) purposed ECM based on DRT analysis. Fig.1a and $b$ based on data from [3].

For quantitative evaluation EIS spectra were fitted to an electrical circuit model (ECM) [35] with the ZView ${ }^{\circledR}$ software.

\subsubsection{Kramers-Kronig validity test}

In order to extract correct physical quantities from the EIS data set, the measured data should be of high quality and show a good signal-to-noise ratio [22]. A rigorous way of proof is to pass the Kramers-Kronig validity test [19, 36]. The relationship between the real $\left(Z_{\text {real }}\right)$ and imaginary $\left(Z_{\text {im }}\right)$ parts of the EIS data set, fulfilling the conditions of linearity, causality and time-invariance, is given by [37]:

$Z_{\text {real }}(\omega)=\frac{2}{\pi} \cdot \int_{0}^{\infty} \frac{\omega^{\prime} \cdot Z_{i m}\left(\omega^{\prime}\right)}{\omega^{2}-\omega^{\prime 2}} d \omega^{\prime}$

$Z_{\text {im }}(\omega)=-\frac{2}{\pi} \cdot \int_{0}^{\infty} \frac{\omega \cdot Z_{\text {real }}\left(\omega^{\prime}\right)}{\omega^{2}-\omega^{\prime 2}} d \omega^{\prime}$

where $Z_{\text {real }}(\omega)$ represents the real part of impedance, $Z_{i m}(\omega)$ represents the imaginary part and $\omega$ the angular frequency. It is not possible to solve the semi- 
infinite integrals in equations 5 and 6 analytically [22]. For practical applications the validity test is altered in the way that the Kramers-Kronig transform compliant measurement model is fitted to the measurement data and the relative residuals are considered in (Eqs. 8, 9). A general model consists of series resistor (R) and capacitor (C) elements. The resistors as well as the time constants are fitted to the measured EIS data set [19].

$$
\begin{aligned}
& \Delta_{\text {real }}(\omega)=\frac{Z_{\text {real }}(\omega)-\hat{Z}_{\text {real }}(\omega)}{|Z(\omega)|} \\
& \Delta_{\text {im }}(\omega)=\frac{Z_{\text {im }}(\omega)-\hat{Z}_{\text {im }}(\omega)}{|Z(\omega)|}
\end{aligned}
$$

where $|Z(\omega)|$ represents the absolute value of the EIS data set and $\hat{Z}(\omega)$ the model impedance. The calculations were performed with the freely available MATLAB application Lin-KK Tool [38]. The EIS data were considered to pass the KramersKronig validity test if the residuals did not exceed a value of $0.5 \%$.

\subsubsection{Distribution of relaxation times (DRT) analysis}

The relation between complex impedance $Z(\omega)$ and the distribution function of the relaxation times $Y(\tau)$ is given by $[19,39,40]$ :

$Z(\omega)=R_{0}+Z_{\text {pol }}(\omega)=R_{0}+R_{p o l} \int_{0}^{\infty} \frac{r(\tau)}{1+j \omega \tau} d \tau, \quad$ with $\int_{0}^{\infty} Y(\tau) d \tau=1$

where $R_{0}$ represents the ohmic (frequency-independent) resistance, $Z_{p o l}(\omega)$ is the polarization part of impedance and $R_{p o l}$ the polarization resistance. The time constant of the single R-C element is given by $\tau=R C$, the fraction of the overall polarization resistance with relaxation times between $\tau$ and $\tau+d \tau$ is indicated by the term $\frac{r(\tau)}{1+j \omega \tau} d \tau$. The mathematical problem is the inversion of Eq. 9, which is needed to derive $r(\tau)$ from the measured EIS data. The calculation is based on the Tikhonov 
regulation method and deconvoluted by DRT using a freely available MATLAB application (DRT tools), with the level regularization (regularization parameter) of $1 \cdot 10^{-5}$ [22]. The complete evaluation procedure of EIS data is shown in Fig. 1 where the measured EIS spectra (Fig. 1a) are deconvoluted using DRT analysis (Fig. 1b). In the latter, two processes show charge transfer kinetics of the anode (frequency range $>100 \mathrm{~Hz}$ ) and the cathode (frequency range of $10-100 \mathrm{~Hz}$ ). These two processes are expected since both HOR and ORR occur during the operation and both are indicated by their own respective resistance $(R)$ and capacitance $(C)$. The response from DRT analysis is calculated with the suitable ECM (Fig. 1c).

\subsection{Post-mortem optical analysis}

To compare the influence of the starvation/regeneration routine after 1 day of cycling (DPS-1) [7] and 12 days of cycling (DPS-2) the anode CLs of both were characterized with $\mu$-CT, FIB-SEM tomography and TEM.

The $\mu$-CT measurements were achieved using the Skyscan 1172 micro-X-ray tomograph (Desktop Micro-CT, Bruker, Belgium). The samples on the FC were punched out in two different MEA regions $(\varnothing 4 \mathrm{~mm})$ near the gas inlet and outlet (Fig. 2a). The operational settings for post-mortem ( $\mu$-CT and FIB-SEM) measurements are summarized in Table 1 [41]. 
Tab.1: Operational settings for $\mu-C T$ and FIB-SEM analyses.

\begin{tabular}{|c|c|c|}
\hline \multicolumn{3}{|c|}{$\mu-C T$} \\
\hline Parameter & Value & Unit \\
\hline Acceleration voltage & $78-82$ & $\mathrm{kV}$ \\
\hline Source current & $96-102$ & $\mu \mathrm{A}$ \\
\hline Sample size $\varnothing$ & $4-5$ & $\mathrm{~mm}$ \\
\hline Rotation step & 0.2 & $\circ$ \\
\hline Random movement & 10 & - \\
\hline Averaging & 4 & - \\
\hline Optical resolution & 1.23 & $\mu m \cdot p x^{-1}$ \\
\hline Duration & $140-180$ & $\min$ \\
\hline \multicolumn{3}{|c|}{ FIB-SEM } \\
\hline Parameter & Value & Unit \\
\hline Ion beam & \multicolumn{2}{|c|}{$\mathrm{Ga}$} \\
\hline Accelerating voltage & 30 & $\mathrm{kV}$ \\
\hline Current & 200 & $\mathrm{pA}$ \\
\hline Average pixel size & 21 & $\mathrm{~nm}$ \\
\hline Sample size $\varnothing$ & $5-6$ & $\mathrm{~mm}$ \\
\hline Mill region & $15 \times 15$ & $\mu \mathrm{m}^{2}$ \\
\hline Duration & 60 & sec \\
\hline
\end{tabular}

The FIB-SEM images were taken with a Zeiss Scanning Electron Microscope (Neon 40 ESB Crossbeam). A focused $\mathrm{Ga}^{+}$ion beam was used to remove layers with defined thickness (milling procedure) at regions of ca. $15 \times 15 \mu \mathrm{m}^{2}$ (Fig. 2b). Consecutive images were acquired under $30 \mathrm{kV}$ accelerating voltage. $\mu$-CT allows a non-destructive view into FC layers and the measure of the thicknesses of different layers and FIB-SEM allows the progressive milling procedure across the FC layer structure [42]. Hence FIB-SEM measurements reveal the structure of the surface and were evaluated as 2D surface and 3D volume due to progressive milling. 


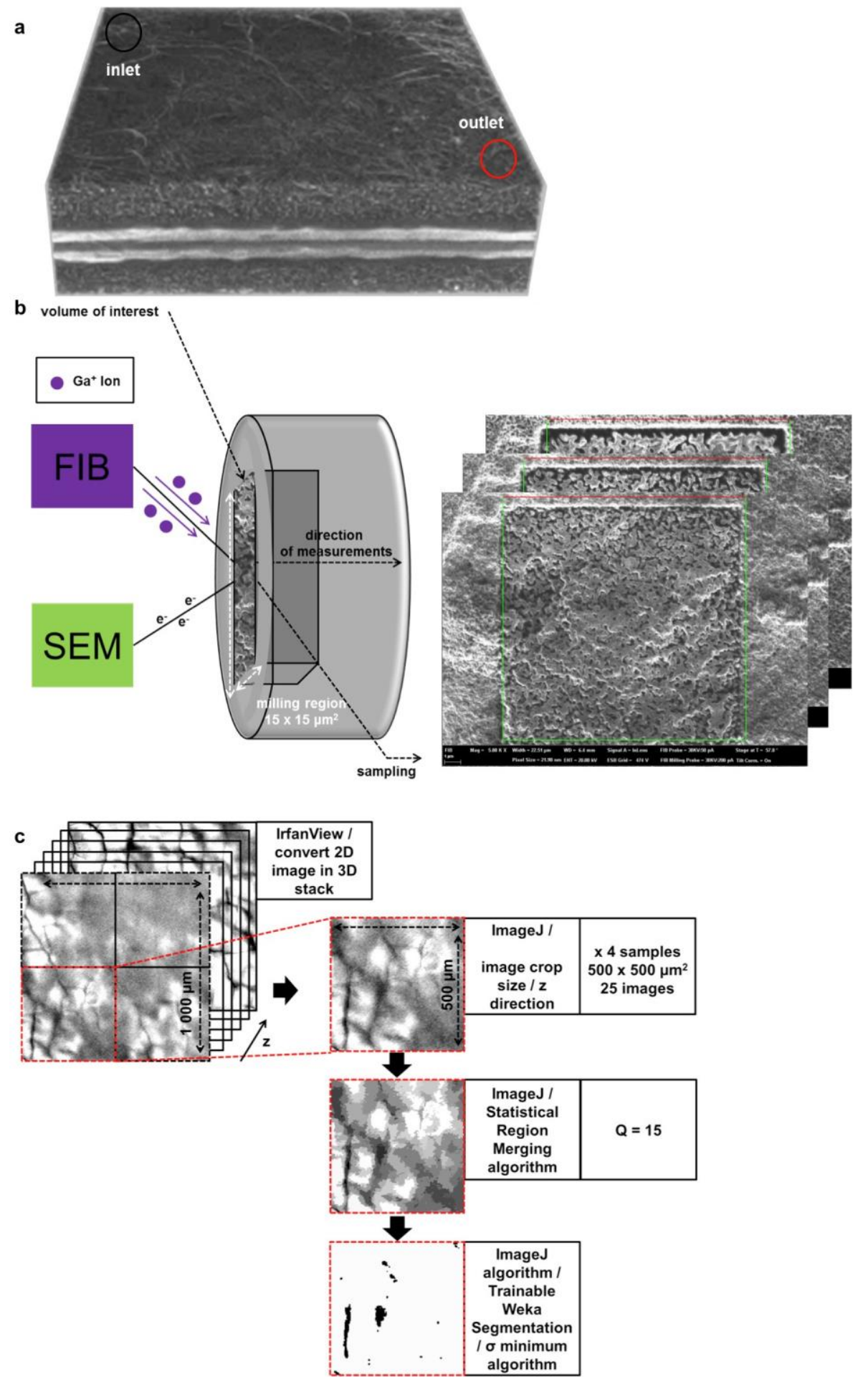

Fig. 2: a) Schematic presentation of an examplary 3D volume of a FC image as well as b) set-up of progressive FIB milling procedure and FIB imaging of a sample surface and obtained surfaces (Fig. $2 b$ adapted from $[42,43]$ ) and c) exemplary flow chart of the processing steps for volume fraction and tortuosity calculation: original volume datasets (in 2D/3D view) and segmentation procedure. 
TEM measurements were performed for each MEA each at the inlet and outlet regions (see introduction section) using the EM 902A (Carl Zeiss AG, Germany) device with a tungsten cathode and CCD camera. An acceleration voltage of $80 \mathrm{kV}$ was used. The samples were prepared by suspending the catalyst in ethanol and placing a drop on a polyvinylformal coated $\mathrm{Cu}$ grid (200 mesh, Plano $\mathrm{GmbH}$, Germany). After the evaporation, the catalyst coated grids were transferred into the TEM device for the measurements [44].

\subsubsection{Volume fraction and tortuosity evaluation}

In order to obtain comparable and meaningful results (due to e.g. various tomography methods) the samples had to go through processing steps, which included segmentation algorithms (Fig. 2c). The single images obtained by $\mu$-CT were transformed into an image stack (volume) with the help of IrfanView software. The original volume datasets were cropped into four samples with the area of $25 \cdot 10^{4} \mu \mathrm{m}^{2}$. Hence four samples from the same MEA region were available for further volume fraction and tortuosity evaluation. As the next step the statistical region merging algorithm (ImageJ/Fuji [45]) was used in order to segment the image into regions of similar intensity or color, with the number of estimated regions (Q) of 15 [46], which were processed with the software Trainable Weka Segmentation (TWS) using the minimum training feature $[47,48]$ into a solid volume (white phase) and a void volume (black phase). To avoid segmentation errors each of the cut samples was processed twice with TWS steps. These processing steps were identical for each of the tomography samples presented here.

The samples from the processing steps allowed the calculation of phase percentages and the quantification of microstructural dimensions [49]. The volume fraction and tortuosity value were calculated with the help of the TauFactor MatLab application 
[25]. Further, the gas diffusion in the investigated samples was simulated in throughplane direction (Fig. 2c, z direction), which is similar to real conditions according to the single cell in operation.

However, the determination of the tortuosity is only possible within the volume under investigation if it shows a large number of pathways. Hence, the determination is obviously not possible if the volume approaches $100 \%$ solid phase fractions. The tortuosity values were calculated for the $\mu$-CT volume which included 25 slides (images) of $600 \mu \mathrm{m} \times 600 \mu \mathrm{m}^{2}$ and for the FIB SEM volume, which included 22 slides (images) of $14 \mu \mathrm{m} \times 14 \mu \mathrm{m}^{2}$. For the FIB SEM volume analysis the image cutting step was not carried out.

\section{Results and discussions}

\subsection{Electrochemical characterization}

Two HT-PEM FCs (DPS-1 and DPS-2) were operated for $~ 550$ minutes with up to 14 starvation steps according to the above described starvation/regeneration routine. During day 1 DPS-1 and DPS-2 showed nearly identical voltage values (Fig. 3a). Subsequently, for DPS-2 the routine was extended to 12 days (Fig. 3a). During regeneration the voltage of DPS-2 varied to a larger extent within the 12 days cycling (Fig. 3a); on the first day the voltage remained stable ( 0.5 to $0.6 \mathrm{~V}$ ), however, it often decreased to $0.4 \mathrm{~V}$ on day 5 and even to $0.1 \mathrm{~V}$ or lower from day 7 onwards (Fig. 3a, green arrow). Despite the sufficient supply of both gases such low voltage values indicate incomplete regeneration from the prior starvation steps probably related to structural changes in the $\mathrm{CL}[4,5]$. 


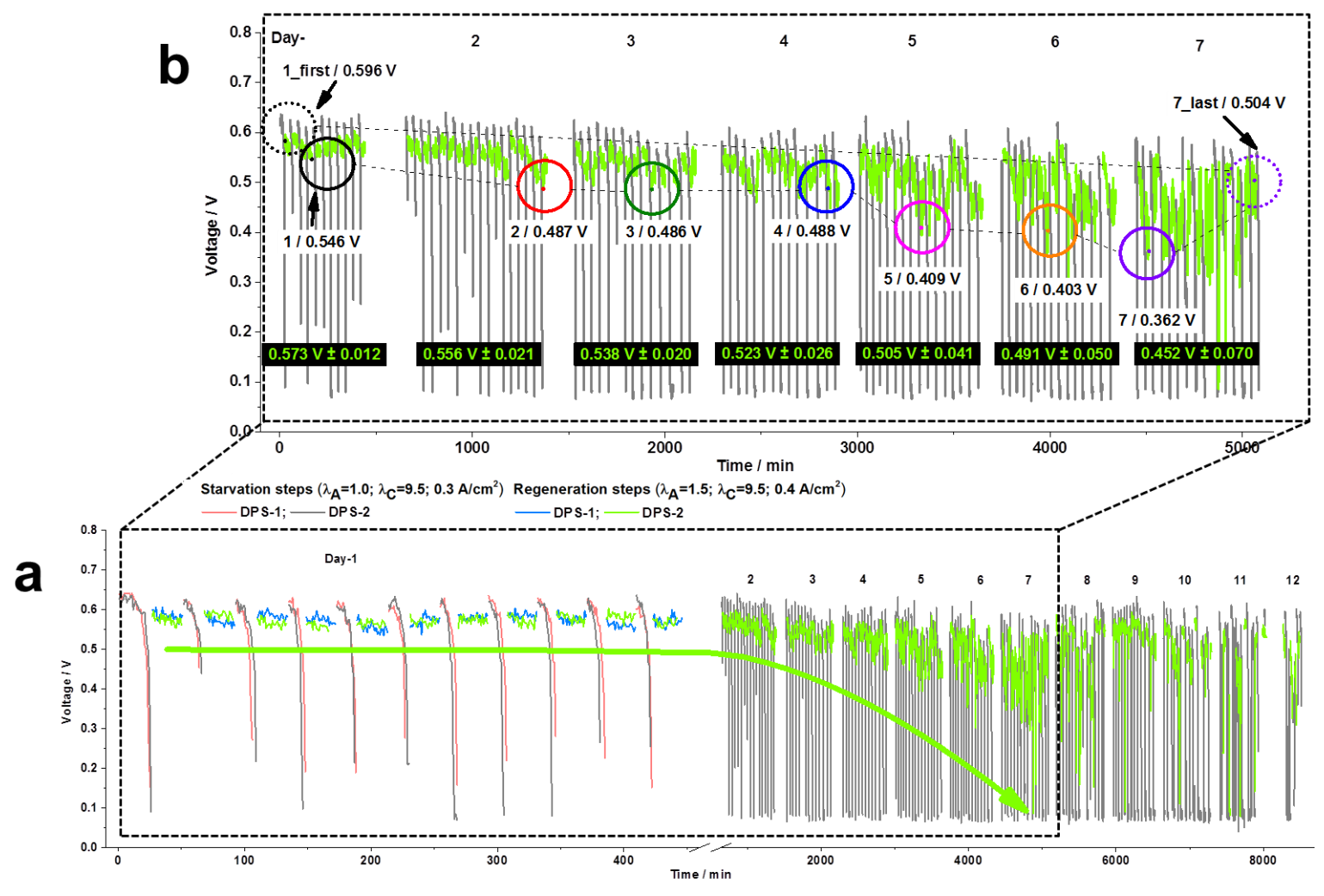

Fig. 3: Voltage versus time for a) DPS-1 and DPS-2 for ca. $550 \mathrm{~min}$ (data from [7]) and b) DPS-2 for days 1-7. Colored circles in b) highlight voltages, for which additional electrochemical measurements were evaluated.

Hence, the low values on days 7 likely indicate an instable running FC. During days 8-12 the voltage often decreases to $0.1 \mathrm{~V}$ or lower. Since the voltage drops for the first time to $0.1 \mathrm{~V}$ on day 7 , it can be assumed that structural changes in FC occurred mostly during days $1-7$. Hence, for electrochemical evaluation the regeneration steps from days 1 to 7 were selected (Fig. 3b). For simplicity reasons, voltage decrease and fluctuations are shown as average value and standard deviation, respectively (Fig. 3b, black squares). The standard deviation increased from day 1 to day 7 , which clearly reflects the instability of the operating FC under reference conditions during regeneration.

The regeneration steps from the 7 days with lowest voltage values were selected from which the minute with the lowest voltage values was chosen for evaluation of 
the impedance spectra (Fig. 3b). Additionally, the first regeneration minute (day 1) and the last minute (day 7 ) of the routine were compared (Fig. 3b).

The chosen minutes had to fulfill two selection criteria: i) lowest voltage value above $0.2 \mathrm{~V}$ (because below this value EIS cannot be recorded), and ii) all selected EIS spectra pass the Kramers-Kronig validity test [19]. For all the selected minutes the EIS spectra showed residuals of $\leq 0.5 \%$ in the Kramers-Kronig validity tests and were, thus, considered to be valid for further evaluation (the results from the Kramers-Kronig tests are presented in supplementary Fig. S1).

Hence, the valid impedance spectra with their respective DRT spectra are shown in Fig. 4. The selected Nyquist spectra show a shift towards higher resistances during the course of the FC cycling (Fig. $4 \mathrm{a}, Z_{\text {real }}$ ). There are two exceptions for days 4 and 6 (Fig. 4a, blue and orange lines) where the Nyquist spectra shift back to lower resistances, an explanation for that will be given at the end of section 3.2.

The corresponding DRT spectra clearly show the presence of two expected polarization processes in the intermediate frequency range $(10 \mathrm{~Hz}$ being related to charge transfer kinetics at the cathode) and in the high frequency range (100 Hz being related to charge transfer kinetics at the anode) (Fig. 4b) [21-23]. During the 7 days, the peak at $10 \mathrm{~Hz}$ increases in intensity while the peak at $100 \mathrm{~Hz}$ shows both an increase in intensity and a shift towards higher frequencies.

On day 3 an additional peak appears at ca. $300 \mathrm{~Hz}$, which is visible again on day 5 (ca. at $700 \mathrm{~Hz}$ ) and 7 (ca. at $800 \mathrm{~Hz}$ ). Such a peak can be linked to an additional process at the anode, with its own series of resistor $(R)$ and capacitor $(C)$ elements. To clarify the origin of the additional process possible reactions at the anode have to be considered. Since $\mathrm{H}_{2}$ is sufficiently supplied during regeneration such peak could indicate the formation of an additional surface at the anode, likely during cell voltage 
reversal and COR of the anode catalyst support [2, 6, 7]. In general, COR can lead to surface oxide formation while Pt nanoparticles may also catalyze COR [18, 50]. Therefore, the additional peaks from 300 through $800 \mathrm{~Hz}$ point to these processes, which are explained in detail as follows:

Pandy et al. [50] assume that carbon support surfaces consist of defect sites $C^{*}$ that are prone to reversible electrochemical oxidation forming unstable $\mathrm{C}-\mathrm{OH}$ groups (Eq. 11) which can be further oxidized to stable $C=O$ groups (Eq. 12).

$\mathrm{C}^{*}+\mathrm{H}_{2} \mathrm{O} \leftrightarrow \mathrm{C}-\mathrm{OH}+\mathrm{H}^{+}+e^{-}$

$C-O H \leftrightarrow C=O+H^{+}+e^{-}$

The carbon hydroxide groups $(\mathrm{C}-\mathrm{OH})$ can form carbon dioxide $\left(\mathrm{CO}_{2}\right)$ and consequential $\mathrm{COR}$ via two stages. The unstable $\mathrm{C}-\mathrm{OH}$ group can be oxidized to form $\mathrm{CO}_{2}$ leaving behind new defect sites $C^{*}$ (Eq. 13).

$\mathrm{C}^{*}-\mathrm{C}-\mathrm{OH}+\mathrm{H}_{2} \mathrm{O} \rightarrow \mathrm{C}^{*}+\mathrm{CO}_{2}+3 \mathrm{H}^{+}+3 e^{-}$

Another possibility could be the formation of $\operatorname{Pt}(\mathrm{OH})_{a d s}$, which acts as an intermediate (Eqs. 14-15). Further, $\mathrm{Pt}(\mathrm{OH})_{a d s}$ may react with the unstable surface oxide of carbon $\mathrm{C}-\mathrm{OH}$ to form again $\mathrm{CO}_{2}$ and carbon defect sites (Eq. 16) [51].

$\mathrm{Pt}+\mathrm{H}_{2} \mathrm{O} \leftrightarrow \mathrm{Pt}(\mathrm{OH})_{a d s}+H^{+}+e^{-}$

$\operatorname{Pt}(\mathrm{OH})_{a d s} \leftrightarrow \mathrm{PtO}_{a d s}+H^{+}+e^{-}$

$\mathrm{C}^{*}-\mathrm{C}-\mathrm{OH}+\mathrm{Pt}(\mathrm{OH})_{a d s} \rightarrow \mathrm{C}^{*}+\mathrm{CO}_{2}+\mathrm{Pt}+2 \mathrm{H}^{+}+2 e^{-}$

In summary, surface oxide formation results from reaction intermediates of the COR that can simplified be written as the formation of the surface functional groups followed by subsequent oxidation to $\mathrm{CO}_{2}[12]$. 

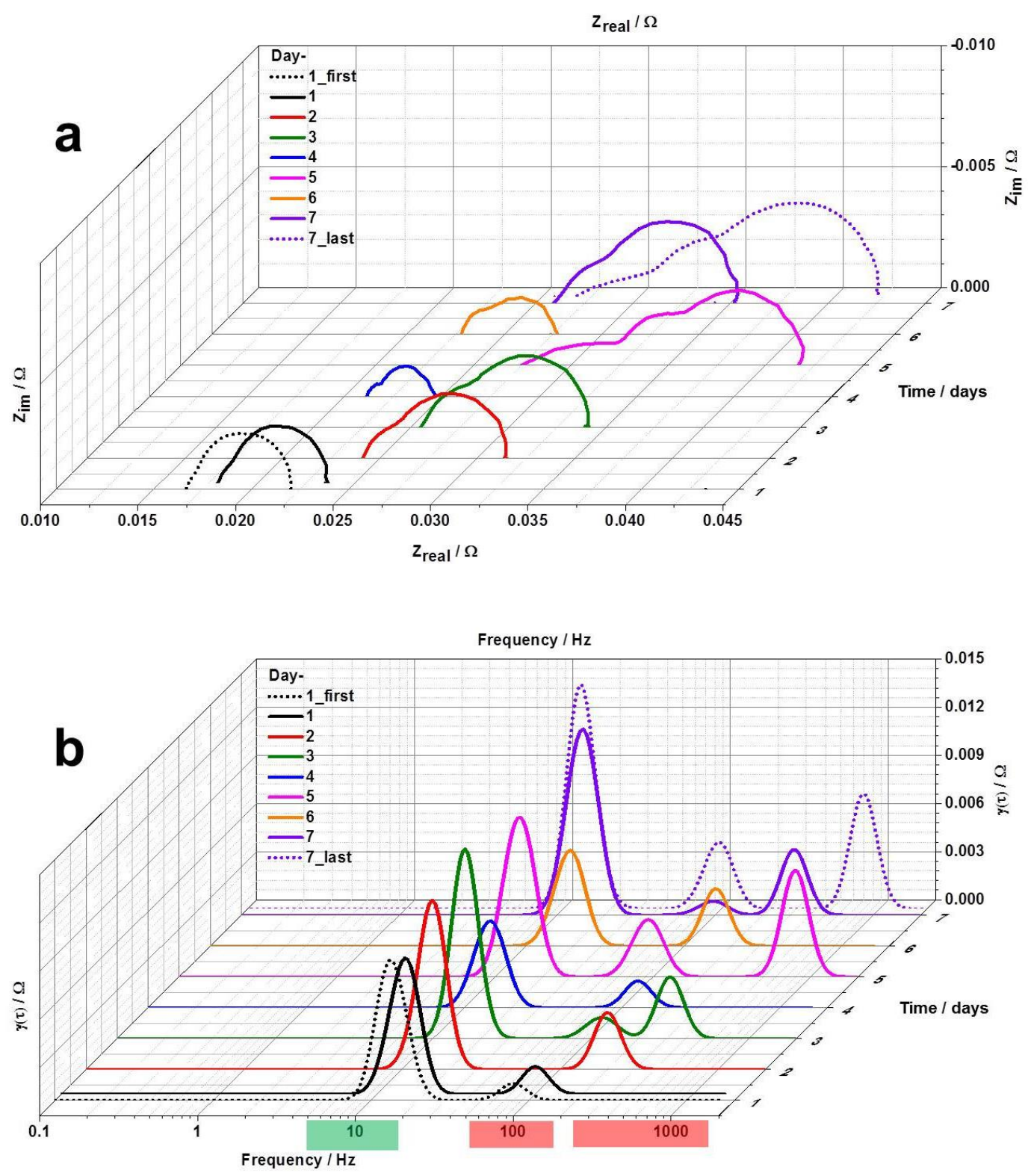

Fig. 4: a) Nyquist spectra for the lowest voltage value from selected regeneration steps (day 1-7) and b) DRT analysis results for those EIS spectra.

By contrast, both Nyquist and DRT spectra of days 4 and 6 show neither an increase in intensity nor additional peaks (Fig. 4a, b). These comparable exceptions from the overall trend will be explained with the help of post-mortem analysis in section 3.2. We further note that peaks in the low frequency range (ca. $1 \mathrm{~Hz}$ ) are absent suggesting that mass transport limitations did not occur at any time. 
The expected peaks (at 10 and ca. $100 \mathrm{~Hz}$, compare Fig. 1b) and the additional peak (at $300-800 \mathrm{~Hz}$ ) suggest three processes. Given the number and intensity of the DRT peaks the suitable process-related ECM was established with which the original Nyquist plots were re-evaluated (see Fig. 1). The evolution of ohmic resistance $\left(R_{\Omega}\right)$, charge transfer resistance at the anode $\left(\mathrm{R}_{\mathrm{h.f.}}\right)$, the additional process at the anode $\left(R_{h . f . a d d i t i o n a l}\right)$ and charge transfer resistance at the cathode $\left(R_{i . f .}\right)$ during the seven days of operation are shown in Fig. 5 where the following becomes apparent. The purposed process-related ECM does not include the mass transport limitation part $\left(R_{\text {I.f. }}\right)$, since no peaks in the low frequency range (ca. $1 \mathrm{~Hz}$ ) occur. This is according to Weiß et al. [22] who showed that when the gas supply was changed from $\mathrm{H}_{2} /$ Air to $\mathrm{H}_{2} /$ pure $\mathrm{O}_{2}$ the peak at $1 \mathrm{~Hz}$ completely disappeared. Since the focus of our manuscript was mainly on processes at the anode we used $\mathrm{O}_{2}$ oversupply for the clear separation of degradation phenomena. Due to setup of the measurement the assumption could be made that no mass transport limitation will occur (due $\mathrm{O}_{2}$ oversupply). That was proven in the experimental part, where no mass transport limitation peaks were visible for the presented EIS response at the start of experiment and during all the 12 days of cycling. 
DPS-2 / regeneration steps $\left(\lambda_{A}=1.5 ; \lambda_{C}=9.5 ; 0.4 \mathrm{~A} / \mathrm{cm}^{2}\right)$

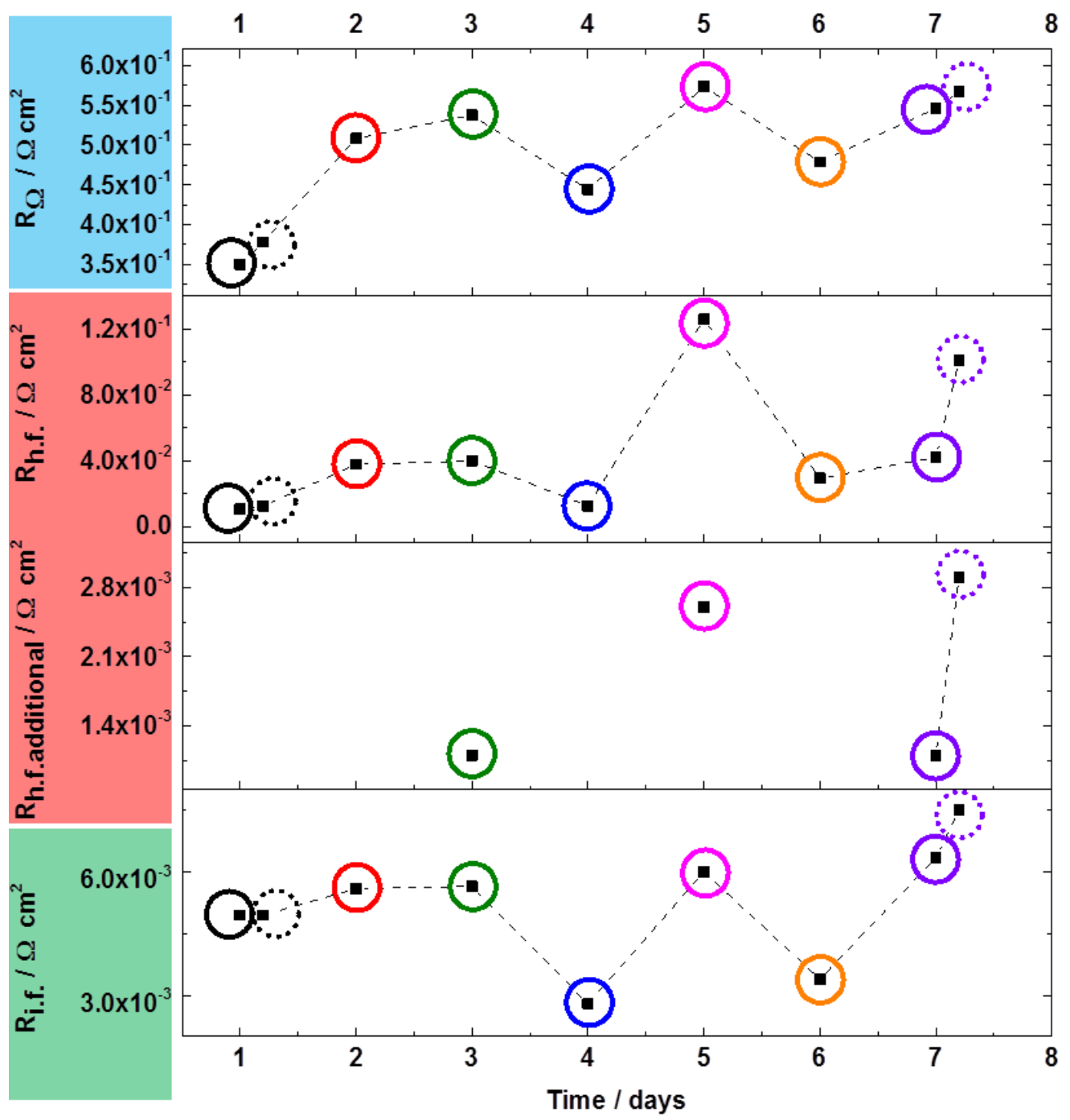

Fig. 5: Resistance values for different processes calculated from the DRT-based ECM.

(i) Ohmic resistance $R_{\Omega}$ increases from $0.347 \Omega \cdot \mathrm{cm}^{2}$ to $0.572 \Omega \mathrm{cm}^{2}$. (ii) The charge transfer kinetics of the anodic HOR $\left(R_{\text {h.f. }}\right)$ increases in resistance from $0.009 \Omega \mathrm{cm}^{2}$ to $0.126 \Omega \mathrm{cm}^{2}$. (iii) The additional process $\left(R_{\text {h.f.additional }}\right)$ at the anode shows a slight increase in resistance from 0.001 to $0.003 \Omega \mathrm{cm}^{2}$ while (iv) there are differences in transfer kinetics of the cathodic ORR (from ca. 0.005 to ca. $0.007 \Omega \mathrm{cm}^{2}$ ). Consequently, all resistances increase over time (with few exceptions), which are referred to in the next chapter. 


\subsection{Post-mortem characterization}

Carbon corrosion, which was indicated by our electrochemical data, is typically accompanied by Pt agglomeration, which can be observed by TEM investigations (Fig. 6). The TEM results show strong agglomeration of Pt particles of anode CL of DPS-2 in comparison to anode CL of DPS-1 (Fig. 6). The Pt particle sizes increased much more at the gas outlet region of the MEA (from $2.8 \pm 1.1$ to $10.3 \pm 6.9 \mathrm{~nm}$ ) than at the inlet region (from $2.5 \pm 0.9$ to $6.8 \pm 5.1 \mathrm{~nm}$ ) confirming COR due to $\mathrm{H}_{2}$ starvation. These results are in line with results of [7] where local current differences between inlet and outlet region during the starvation were discussed. In addition, the observed Pt particle size distribution in DPS-2 is comparable with the result of [52] where similar Pt particle sizes were found after harsh cycling/degradation.
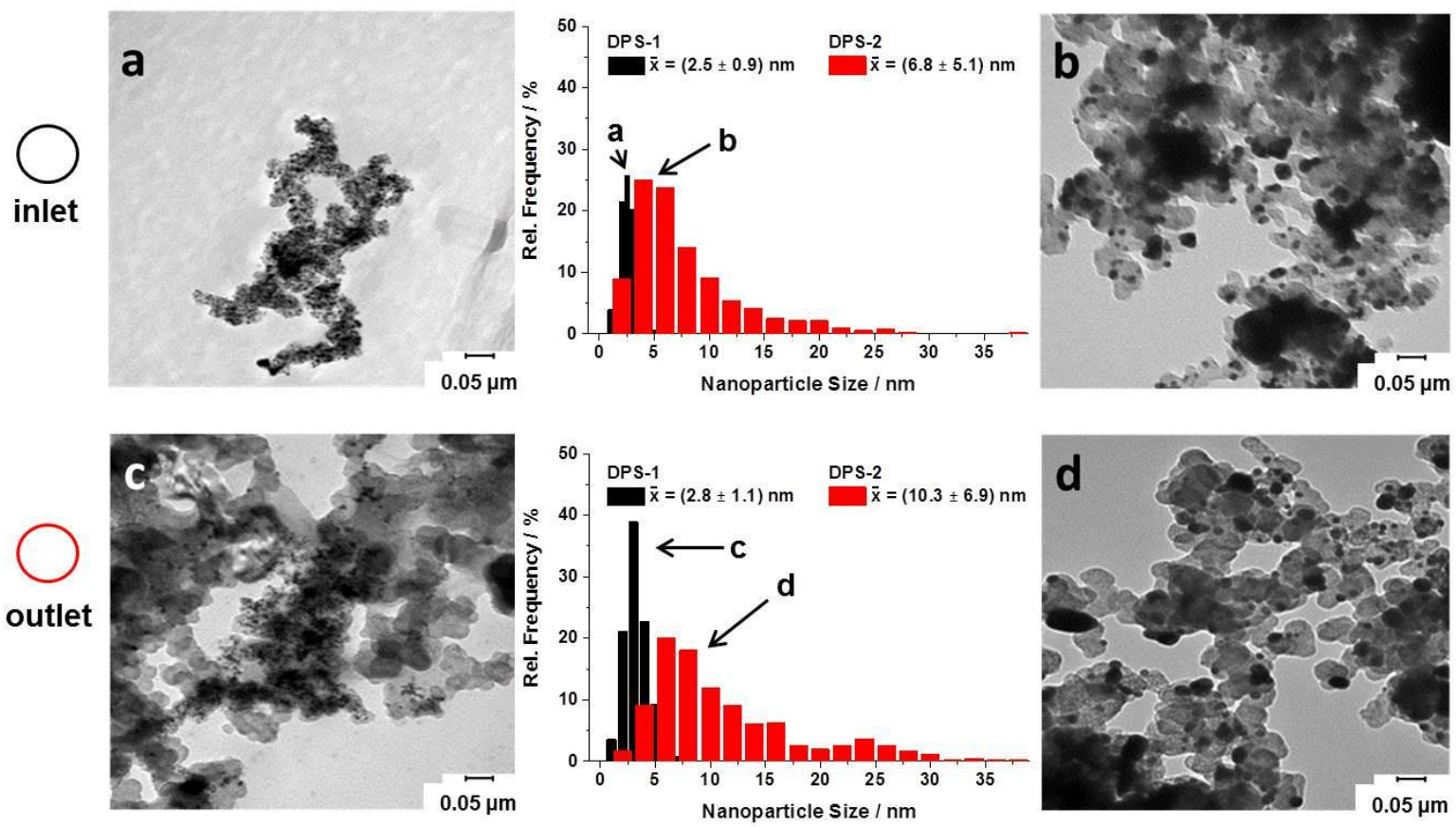

Fig. 6: TEM images and Pt particle size distributions for anode inlet CL: a) DPS-1, b) DPS-2 and for anode outlet CL c) DPS-1 and d) DPS-2.

Additional information on the extent of carbon corrosion and $\mathrm{CL}$ degradation comes from 2D gray scale images of FIB-SEM measurements (Fig. 7a-e). The CL structures 
visually appear to be similar to those from Zielke et al. [53], who reconstructed CL and MPL volumes using FIB-SEM analysis. 

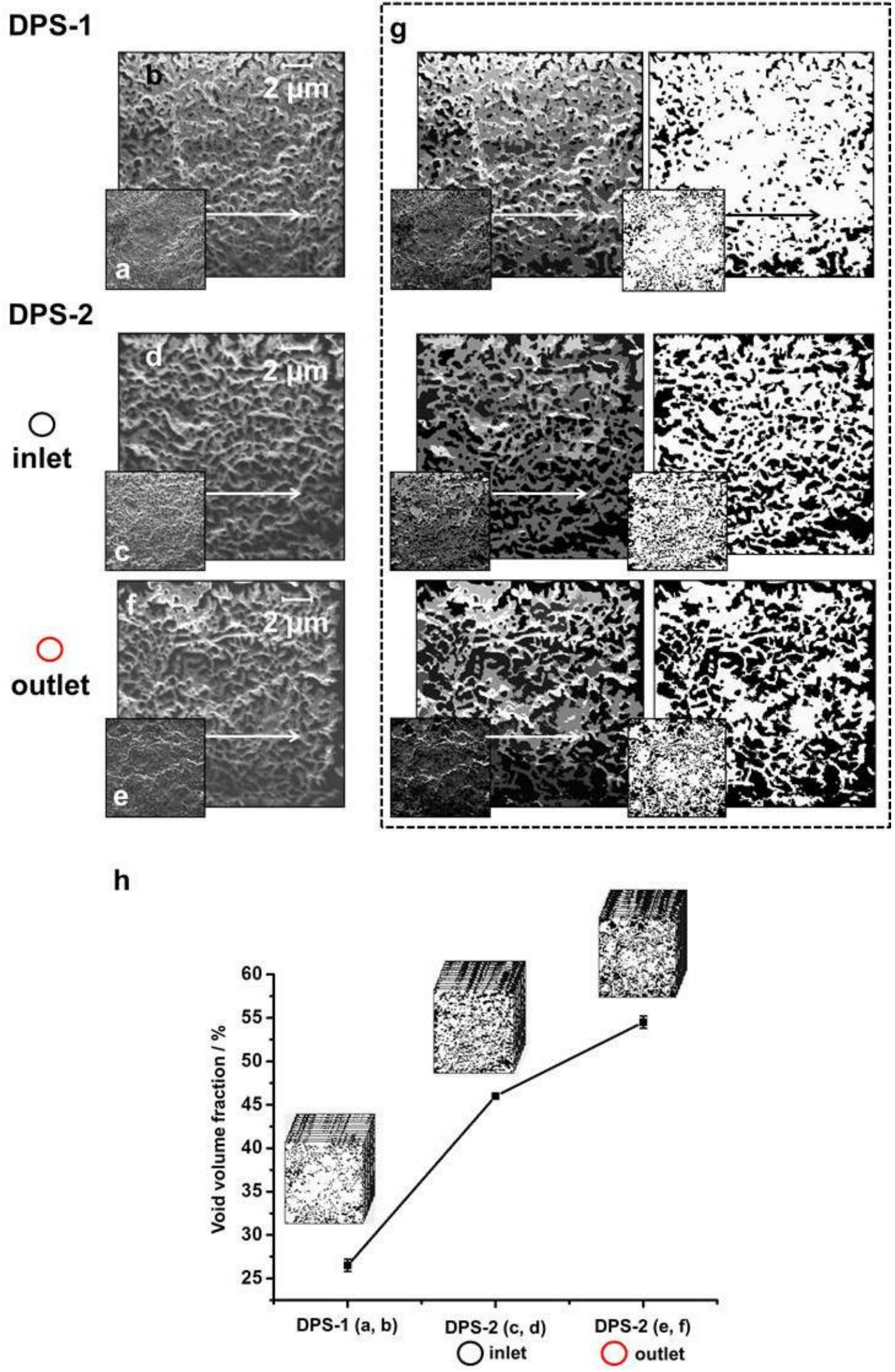

Fig. 7: FIB-SEM images for a-b) DPS-1; c-d) DPS-2 inlet; e-f) DPS-2 outlet (images a,c,e depict top layers of CLs); g) preparing steps for volume fraction calculation for corresponding samples and h) void volume fractions for evaluated sample regions. 
In comparison to the anode CL of DPS-1 (Fig. 7b) the anode CL inlet (Fig. 7d) and outlet (Fig. 7f) in DPS-2 show slightly higher porosity (Fig. 7g). The corresponding void volume fraction values (DPS-1 and DPS-2) are shown in Fig. $7 \mathrm{~h}$. While the void volume fraction of the DPS-2 inlet clearly exceeds that of the DPS-1 inlet (46\% compared to $27 \%$ ) the void volume fraction of the DPS-2 outlet is only slightly increased (55\%) in comparison to the DPS-2 inlet. The increase of void volume fraction probably points to the influence of $\mathrm{COR}$ during $\mathrm{H}_{2}$ starvation. Since COR points to $\mathrm{Pt}$ agglomeration such result is in line with the TEM results where $\mathrm{Pt}$ agglomeration is much more pronounced at DPS-2 outlet than at DPS-2 inlet.

Similarly to FIB-SEM, $\mu$-CT can visualize the layers as $2 \mathrm{D}$ surface and in $3 \mathrm{D}$ volume. This allows confirmation of the result from FIB-SEM and also provides ideas about structural changes at the macro scale (Fig. 8a-f). The 2D layers of the CLs at the DPS-1 anode inlet (Fig. 8a,b) are compared with those of the DPS-2 anode CLs (Fig. 8c-f) showing advanced crack formation [54] after 12 days cycling (DPS-2). The widths of formed cracks are in the range of ca. 5-60 $\mu \mathrm{m}$ (Figs. 8d, f). According to $[55,56]$ cracks with widths in the range of $20-30 \mu \mathrm{m}$ are typical for CLs in HT-PEM FC and have only slight impact on the FC performance. However, here the widths of some cracks are by about $30 \mu \mathrm{m}$ higher than the typical range, hence the increased amount of cracks not only increases the void volume and decreases the tortuosity of the $\mathrm{CL}$ (Figs. 8g, h), but might also point to a loss in performance. The advanced crack formation directly influences the void volume and formation of new electrochemically active surface area (ECSA). Detailed investigation of ECSA changes can be done by e.g. using cyclic voltammetry (CV) [10, 44], which was, however, not chosen due to unwanted additional degradation potential resulting from this method [57-59]. 
The values for tortuosity are $5 \pm 1.9$ for inlet region and $2 \pm 0.3$ for outlet region (Fig. $8 \mathrm{~h})$ after degradation. The values are comparable to those found in [60], where the CL morphology of low temperature fuel cells (LT-PEM FCs) was studied. An inversely proportional dependency of void volume fraction and tortuosity was also reported by [61] for solid oxide fuel cells (SOFCs). Thus, our results confirm that the outlet region of DPS-2 is more degraded than the inlet region due to COR.

Our electrochemical data together suggest that carbon corrosion, and especially crack formation, may not be a progressive, linear process but a rather unsteady one with large fluctuations. Therefore, the results from FIB-SEM and $\mu$-CT tomography may help to explain the exceptions from the overall trend for days 4 and 6 in the impedance measurements (Figs. 4a,b and 8). Hence, it is assumed that due to "sudden" crack formation some new electrochemically active surface area with freshly accessible Pt particles is exposed, which likely decreases the resistance at the anode for a short and transient time period. 
DPS-1

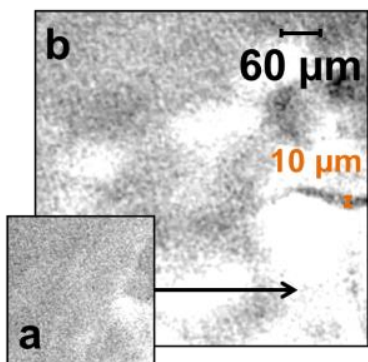

DPS-2

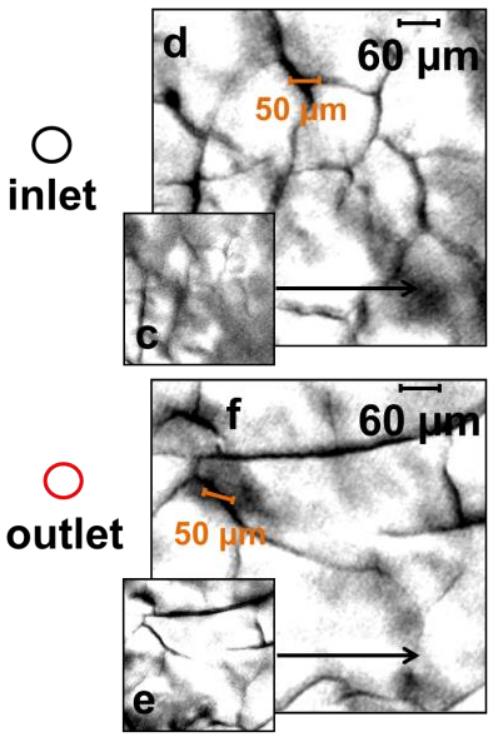

g
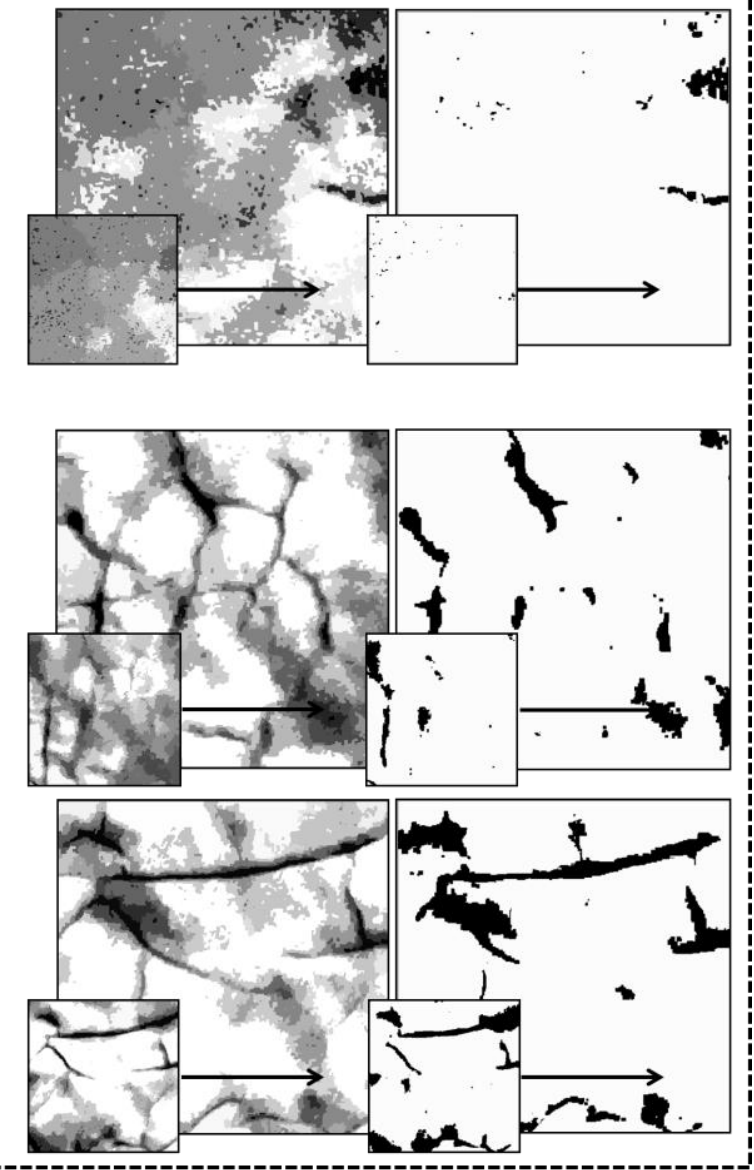

h

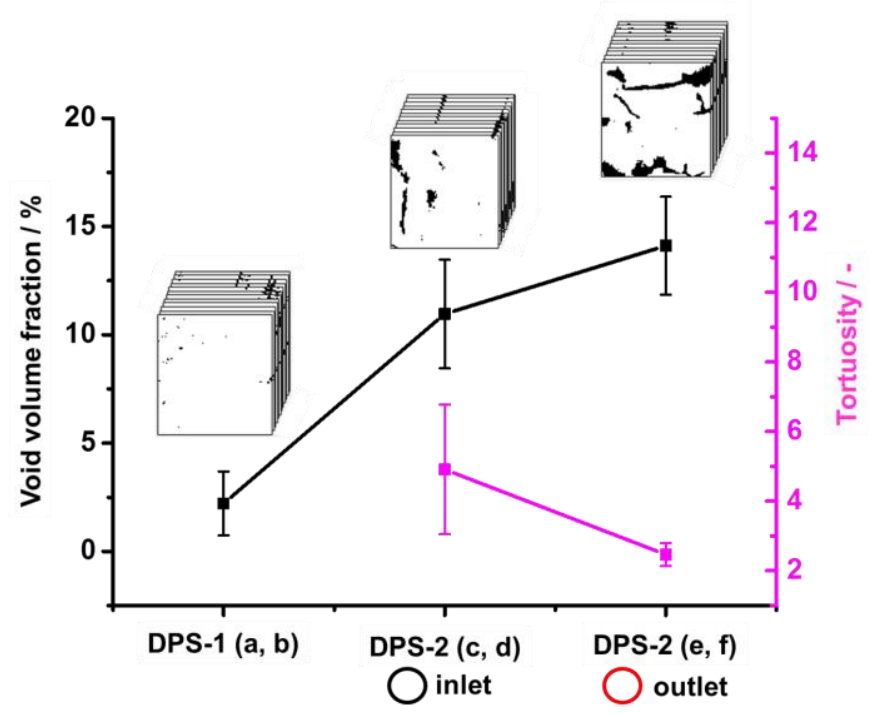

Fig. 8: $\mu$-CT images for a-b) DPS-1; c-d) DPS-2 inlet; e-f) DPS-2 outlet (images a,c,e depict top layers of CLs); g) preparation steps for volume fraction and tortuosity calculation for corresponding samples and $\mathrm{h}$ ) void volume fraction and tortuosity value for evaluated sample regions. 


\section{Conclusions}

Two HT-PEM FCs were operated under repeated $\mathrm{H}_{2}$ starvation/regeneration steps (DPS-1 for 550 minutes and DPS-2 for 12 days). During the first 550 minutes both FCs showed identical performance as seen by essentially the same output voltages. During days 1 and 7 DPS-2 decreased in performance (from 0.6 to $0.1 \mathrm{~V}$ ) and remained highly unstable (fluctuations between 0.6 and $0 \mathrm{~V}$ ) during days 8 and 12 . Hence, we assume that significant degradation took place during the first seven days.

Therefore, the EIS response of selected regeneration steps from the first seven days were evaluated, which showed a shift towards higher resistances. Corresponding DRT spectra showed an intensity increase of the charge transfer kinetics of the cathode (ca. $10 \mathrm{~Hz}$ ) and the anode (ca. $100 \mathrm{~Hz}$ ). From day 3 on, an additional peak at $300-800 \mathrm{~Hz}$ reflected polarization processes at the anode, likely surface oxide formation due to carbon corrosion (COR). The overall performance loss of DPS-2 can be explained by the EIS response, where an increase of resistances, especially at the anode of up to $0.126 \Omega \mathrm{cm}^{2}$ occurred.

Post-mortem analyses (TEM, FIB-SEM, $\mu$-CT) were performed for DPS-1 after day 1 and for DPS-2 after day 12. The TEM results revealed strong agglomeration of Pt particles of DPS-2 in comparison to DPS-1, especially in the outlet region, which clearly confirms COR. The obtained FIB-SEM images showed the increase in void volume within the CL. Based on FIB-SEM stack images void volume fractions were calculated, which increased from $27 \%$ (DPS-1) to $55 \%$ (DPS-2, outlet). Further, $\mu$ CT images showed advanced crack formation with crack widths in the range of ca. 5$60 \mu \mathrm{m}$ due to COR. Increased amounts of cracks likely reflect an increase in void volume within the $\mathrm{CL}$. Based on $\mu-\mathrm{CT}$ stacks images void volume fractions and tortuosity values were determined. The void volume fraction increased from $2 \%$ 
(DPS-1) to $11 \%$ (DPS-2, inlet) to $14 \%$ (DPS-2, outlet). In summary, the post-mortem analysis data confirm that the outlet rather than the inlet of the FC is more degraded. This work introduces the regeneration into cycled starvation, which helps to distinguish insignificant from significant degradation occurring in HT-PEM FCs. Electrochemical measurements such as voltage output, impedance spectra and DRT analysis carried out simultaneously during operation allow to better constrain the onset of significant degradation phenomena in FCs online. This diagnostic tool can optimize operational strategies to prevent FC lifetime reduction.

\section{Acknowledgements}

The authors thank the Federal Ministry of Economic Affairs and Energy (Project QUALIFIX, grant ID: 03ET6046A) as well as J. Huelstede, M. Rastedt and S. J. Cooper for kind technical support and useful discussions. 


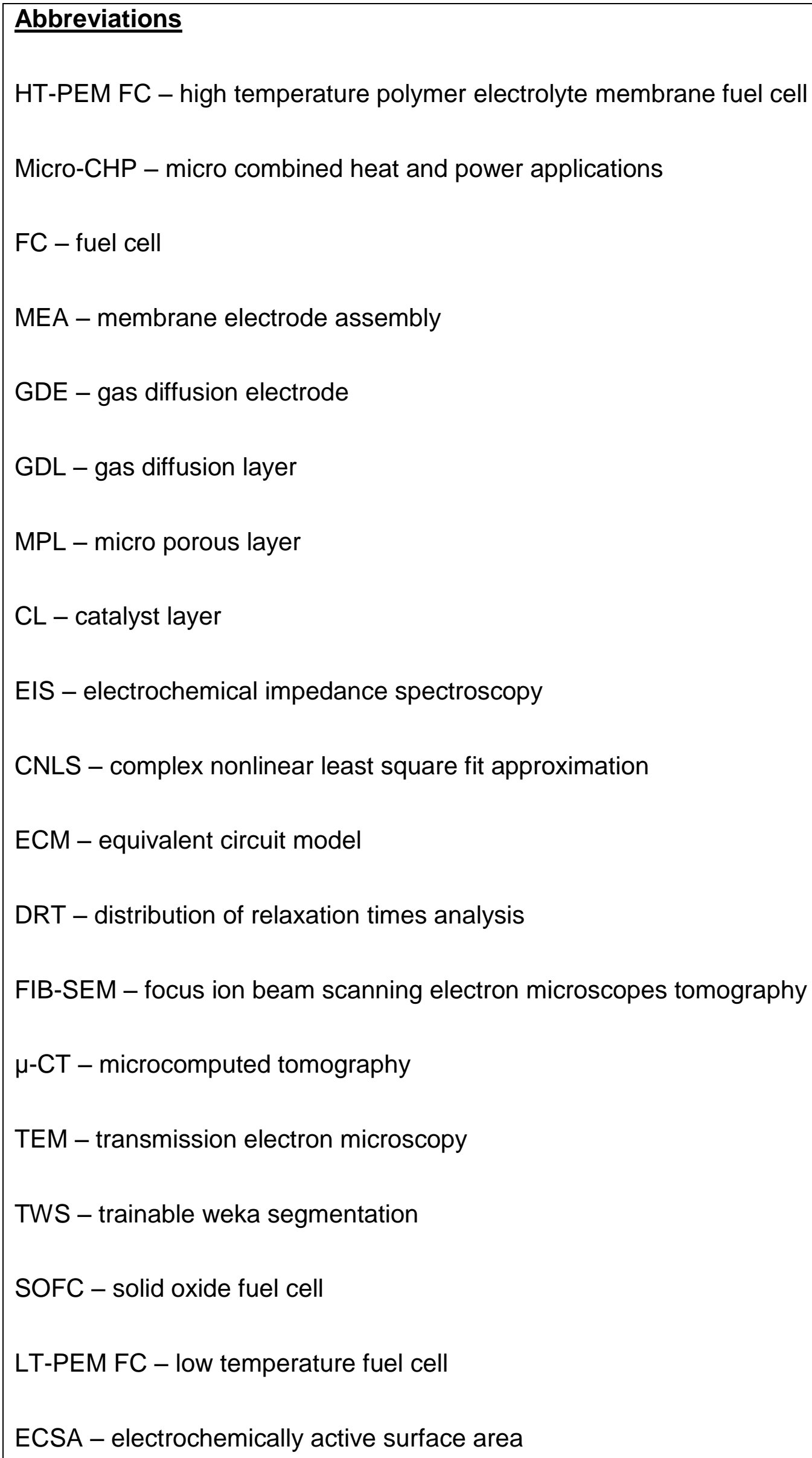


CV - cyclic voltammetry

\section{References}

1. Sahlin SL, Araya SS, Andreasen SJ, Kær SK. Electrochemical Impedance Spectroscopy (EIS) Characterization of Reformate-operated High Temperature PEM Fuel Cell Stack. IJPER. 2017;1(1):20-40; https://doi.org/10.22606/ijper.2017.11003.

2. Engl T, Gubler L, Schmidt TJ. Fuel Electrode Carbon Corrosion in High Temperature Polymer Electrolyte Fuel Cells-Crucial or Irrelevant? Energy Technology. 2016;4(1):65-74; https://doi.org/10.1002/ente.201500217.

3. Simon Araya S, Zhou F, Lennart Sahlin S, Thomas S, Jeppesen C, Knudsen Kær S. Fault Characterization of a Proton Exchange Membrane Fuel Cell Stack. Energies (Open Access Journal). 2019;12(1):152; https://doi.org/10.3390/en12010152.

4. Macauley N, Papadias DD, Fairweather J, Spernjak D, Langlois D, Ahluwalia R, More KL, Mukundan R, Borup RL. Carbon Corrosion in PEM Fuel Cells and the Development of Accelerated Stress Tests. J Electrochem Soc. 2018;165(6):F3148F60; https://doi.org/10.1149/2.0061806jes.

5. Banas CJ, Uddin MA, Park J, Bonville LJ, Pasaogullari U. Thinning of Cathode Catalyst Layer in Polymer Electrolyte Fuel Cells Due to Foreign Cation Contamination. J Electrochem Soc. 2018;165(6):F3015-F23; https://doi.org/10.1149/2.0021806jes.

6. Schwämmlein JN, Rheinländer PJ, Chen Y, Freyer KT, Gasteiger HA. Anode Aging during PEMFC Start-Up and Shut-Down: H2-Air Fronts vs Voltage Cycles. J Electrochem Soc. 2018;165(16):F1312-F22; https://doi.org/10.1149/2.0611816jes.

7. Yezerska K, Dushina A, Liu F, Rastedt M, Wagner P, Dyck A, Wark M. Characterization methodology for anode starvation in HT-PEM fuel cells. Int $\mathrm{J}$ Hydrogen Energy. 2019;44(33):18330-9; https://doi.org/10.1016/j.ijhydene.2019.05.114. 
8. Hong BK, Mandal P, Oh JG, Litster S. On the impact of water activity on reversal tolerant fuel cell anode performance and durability. J Power Sources. 2016;328:280-288; https://doi.org/10.1016/j.jpowsour.2016.07.002.

9. Lim KH, Lee WH, Jeonga Y, Kim H. Analysis of Carbon Corrosion in Anode under Fuel Starvation Using On-Line Mass Spectrometry in Polymer Electrolyte Membrane Fuel Cells. J Electrochem Soc. 2017;164(14): F1580-F1586; https://doi.org/10.1149/2.0731714jes.

10. Taniguchi A, Akita T, Yasuda K, Miyazaki Y. Analysis of electrocatalyst degradation in PEMFC caused by cell reversal during fuel starvation. J Power Sources. 2004;130(1-2): 42-49; https://doi.org/10.1016/j.jpowsour.2003.12.035.

11. Zhou F, Andreasen S, Kær S, Yu D. Analysis of accelerated degradation of a HT-PEM fuel cell caused by cell reversal in fuel starvation condition. Int J Hydrogen Energy. 2015; 40(6): 2833-2839; https://doi.org/10.1016/j.ijhydene.2014.12.082.

12. Maass S, Finsterwalder F, Frank G, Hartmann R, Merten C. Carbon support oxidation in PEM fuel cell cathodes. J Power Sources. 2008;176(2):444-51; https://doi.org/10.1016/j.jpowsour.2007.08.053.

13. Borup R, Meyers J, Pivovar B, Kim YS, Mukundan R, Garland N, Myers D, Wilson M, Garzon F, Wood D, Zelenay P, More K, Stroh K, Zawodzinski T, Boncella J, McGrath JE, Inaba M, Miyatake K, Hori M, Ota K, Ogumi Z, Miyata S, Nishikata A, Siroma Z, Uchimoto Y, Yasuda K, Kimijima K, Iwashita N. Scientific Aspects of Polymer Electrolyte Fuel Cell Durability and Degradation. Chem Rev. 2007;107(10):3904-51; https://doi.org/10.1021/cr050182I.

14. Avasarala B, Moore R, Haldar P. Surface oxidation of carbon supports due to potential cycling under PEM fuel cell conditions. Electrochim Acta. 2010;55(16):476571; https://doi.org/10.1016/j.electacta.2010.03.056.

15. Patterson TW, Darling RM. Damage to the Cathode Catalyst of a PEM Fuel Cell Caused by Localized Fuel Starvation. Electrochem. Solid-State Lett. 2006;9(4): A183-A185; https://doi.org/10.1149/1.2167930.

16. Ralph TR, Hogarth MP. Catalysis for low temperature fuel cells: Part II: The anode challenges. Platinum Metals Rev. 2002;46(3): 117-135. 
17. Tang H, Qi Z, Ramani M, Elter JF. PEM fuel cell cathode carbon corrosion due to the formation of air/fuel boundary at the anode. J Power Sources. 2006;158(2): 1306-1312; https://doi.org/10.1016/j.jpowsour.2005.10.059.

18. Kregar A, Tavčar G, Kravos A, Katrašnik T. Predictive virtual modelling framework for performance and platinum degradation modelling of high temperature PEM fuel cells. Energy Procedia. 2019;158:1817-22; https://doi.org/10.1016/j.egypro.2019.01.426.

19. Heinzmann M, Weber A, Ivers-Tiffée E. Advanced impedance study of polymer electrolyte membrane single cells by means of distribution of relaxation times. J Power Sources. 2018;402:24-33;

https://doi.org/10.1016/j.jpowsour.2018.09.004.

20. Danzer M. Generalized Distribution of Relaxation Times Analysis for the Characterization of Impedance Spectra. Batteries. 2019;5:53; https://doi.org/10.3390/batteries5030053.

21. Jespersen JL, Schaltz E, Kær SK. Electrochemical characterization of a polybenzimidazole-based high temperature proton exchange membrane unit cell. $J$ Power Sources. 2009;191(2):289-96; https://doi.org/10.1016/j.jpowsour.2009.02.025.

22. Weiß A, Schindler S, Galbiati S, Danzer MA, Zeis R. Distribution of Relaxation Times Analysis of High-Temperature PEM Fuel Cell Impedance Spectra. Electrochim Acta. 2017;230:391-8; https://doi.org/10.1016/j.electacta.2017.02.011.

23. Schindler S, Weiß A, Galbiati S, Mack F, Danzer MA, Zeis R. Identification of Polarization Lossesin High Temperature PEM Fuel Cellsby Distribution of Relaxation Times Analysis. ECS Prime; Honolulu, Hawaii2016;

https://doi.org/10.1149/07514.0045ecst.

24. Bertei A, Ruiz-Trejo E, Tariq F, Yufit V, Atkinson A, Brandon NP. Validation of a physically-based solid oxide fuel cell anode model combining 3D tomography and impedance spectroscopy. Int J Hydrogen Energy. 2016;41(47):22381-93;

https://doi.org/10.1016/j.jijhydene.2016.09.100.

25. Cooper SJ, Bertei A, Shearing PR, Kilner JA, Brandon NP. TauFactor: An open-source application for calculating tortuosity factors from tomographic data. SoftwareX. 2016;5:203-10; https://doi.org/10.1016/j.softx.2016.09.002. 
26. Shearing PR, Eastwood DS, Bradley RS, Gelb J, Cooper SJ, Tariq F, Brett DJL, Brandon NP, Withers PJ, Lee PD. Exploring electrochemical devices using Xray microscopy: 3D microstructure of batteries and fuel cells. Microscopy and Analysis. 2013;27:19-22.

27. Shipman W, Nel A, Chetty D, Miller J, Lin C. The application of machine learning to the problem of classifying voxels in X-ray microtomographic scans of mineralogical samples. Proceedings of the 2013 IEEE International Conference on Industrial Technology: IEEE; 2013; https://doi.org/10.1109/ICIT.2013.6505841.

28. Chandan A, Hattenberger M, El-Kharouf A, Du S, Dhir A, Self V, Pollet BG, Ingram A, Bujalski W. High temperature (HT) polymer electrolyte membrane fuel cells (PEMFC) - A review. J Power Sources. 2013;231(0):264-78;

https://doi.org/10.1016/j.jpowsour.2012.11.126.

29. Scholes ON, Clayton SA, Hoadley AFA, Tiu C. Permeability anisotropy due to consolidation of compressible porous media. Transport in Porous Media. 2007;68(3):365-87; https://doi.org/10.1007/s11242-006-9048-5.

30. Büsselmann J, Rastedt M, Tullius V, Yezerska K, Dyck A, Wagner P. Evaluation of HT-PEM MEAs: Load cycling versus start/stop cycling. Int J Hydrogen Energy. 2018; https://doi.org/10.1016/j.ijhydene.2018.07.181.

31. Matyka M, Khalili A, Koza Z. Tortuosity-porosity relation in porous media flow. Phys Rev E. 2008;78(2):026306; https://doi.org/10.1103/PhysRevE.78.026306.

32. Shen $\mathrm{L}$, Chen Z. Critical review of the impact of tortuosity on diffusion. Chem Eng Sci. 2007;62(14):3748-55; https://doi.org/10.1016/j.ces.2007.03.041.

33. Tingeloef $\mathrm{T}$, Ihonen JK. A rapid break-in procedure for PBI fuel cells. Int $\mathrm{J}$ Hydrogen Energy. 2009;34(15):6452-6; https://doi.org/10.1016/j.jijhydene.2009.05.003.

34. Ribeirinha P, Abdollahzadeh M, Sousa JM, Boaventura M, Mendes A. Modelling of a high-temperature polymer electrolyte membrane fuel cell integrated with a methanol steam reformer cell. Appl Energ. 2017;202(Supplement C):6-19; https://doi.org/10.1016/j.apenergy.2017.05.120. 
35. Araya SS, Zhou F, Liso V, Sahlin SL, Vang JR, Thomas S, Gao X, Jeppesen C, Kær SK. A comprehensive review of PBI-based high temperature PEM fuel cells. Int J Hydrogen Energy. 2016;41(46):21310-21344;

https://doi.org/10.1016/j.ijhydene.2016.09.024.

36. Boukamp BA. A Linear Kronig-Kramers Transform Test for Immittance Data Validation. J Electrochem Soc. 1995;142(6):1885-94; https://doi.org/10.1149/1.2044210.

37. Schönleber M, Klotz D, Ivers-Tiffée E. A Method for Improving the Robustness of linear Kramers-Kronig Validity Tests. Electrochim Acta. 2014;131:20-7; https://doi.org/10.1016/j.electacta.2014.01.034.

38. Schönleber M, Ivers-Tiffée E. Approximability of impedance spectra by RC elements and implications for impedance analysis. Electrochem Commun. 2015;58:15-9; https://doi.org/10.1016/j.elecom.2015.05.018.

39. Schichlein H, Müller AC, Voigts M, Krügel A, Ivers-Tiffée E. Deconvolution of electrochemical impedance spectra for the identification of electrode reaction mechanisms in solid oxide fuel cells. J Appl Electrochem. 2002;32(8):875-82; https://doi.org/10.1023/a:1020599525160.

40. Ivers-Tiffée E, Weber A. Evaluation of electrochemical impedance spectra by the distribution of relaxation times. J Ceram Soc Jpn. 2017;125(4):193-201; https://doi.org/10.2109/jcersj2.16267.

41. Rastedt M, Büsselmann J, Tullius V, Wagner P, Dyck A. Rapid and Flash Tests: Indicator for Quality of HT-PEM Fuel Cells Batches? Fuel Cells. 2018;18(2):113-22; https://doi.org/10.1002/fuce.201700177.

42. Wankmüller F, Szász J, Joos J, Wilde V, Störmer H, Gerthsen D, Ivers-Tiffée E. Correlative tomography at the cathode/electrolyte interfaces of solid oxide fuel cells. J Power Sources. 2017;360:399-408;

https://doi.org/10.1016/j.jpowsour.2017.06.008.

43. Friedensen S, Mlack JT, Drndić M. Materials analysis and focused ion beam nanofabrication of topological insulator Bi(2)Se(3). Sci Rep. 2017;7(1):13466; https://doi.org/10.1038/s41598-017-13863-6. 
44. Schonvogel D, Hülstede J, Wagner P, Dyck A, Agert C, Wark M. Durability of Electrocatalysts for ORR: Pt on Nanocomposite of Reduced Graphene Oxide with FTO versus Pt/C. J Electrochem Soc. 2018;165(6):F3373-F82;

https://doi.org/10.1149/2.0361806jes.

45. Schindelin J, Arganda-Carreras I, Frise E, Kaynig V, Longair M, Pietzsch T, Preibisch S, Rueden C, Saalfeld S, Schmid B, Tinevez J, White DJ, Hartenstein V, Eliceiri K, Tomancak P, Cardona A. Fiji: an open-source platform for biological-image analysis. Nat Meth. 2012;9(7):676-82; https://doi.org/10.1038/nmeth.2019.

46. Nock R, Nielsen F. Statistical Region Merging. IEEE transactions on pattern analysis and machine intelligence. 2004;26:1452-8;

https://doi.org/10.1109/TPAMI.2004.110.

47. Arganda-Carreras I, Kaynig V, Rueden C, Eliceiri KW, Schindelin J, Cardona A, Seung HS. Trainable Weka Segmentation: a machine learning tool for microscopy pixel classification. Bioinformatics. 2017;33(15):2424-6;

https://doi.org/10.1093/bioinformatics/btx180.

48. Arganda-Carreras I, Kaynig V, Schindelin J, Cardona A, Seung HS. Trainable Weka Segmentation: A Machine Learning Tool for Microscopy Image Segmentation. 2014.

49. Bertei A, Ruiz-Trejo E, Kareh K, Yufit V, Wang X, Tariq F, Brandon NP. The fractal nature of the three-phase boundary: A heuristic approach to the degradation of nanostructured solid oxide fuel cell anodes. Nano Energy. 2017;38(Supplement C):526-36; https://doi.org/10.1016/j.nanoen.2017.06.028.

50. Pandy A, Yang Z, Gummalla M, Atrazhev VV, Kuzminyh NY, Sultanov VI, Burlatsky S. A Carbon Corrosion Model to Evaluate the Effect of Steady State and Transient Operation of a Polymer Electrolyte Membrane Fuel Cell. J Electrochem Soc. 2013;160(9):F972-F9; https://doi.org/10.1149/2.036309jes.

51. Cai M, Ruthkosky MS, Merzougui B, Swathirajan S, Balogh MP, Oh SH. Investigation of thermal and electrochemical degradation of fuel cell catalysts. $J$ Power Sources. 2006;160(2):977-86; https://doi.org/10.1016/j.jpowsour.2006.03.033. 
52. Bengen N. Degradation von Hochtemperatur-PolymerelektrolytmembranBrennstoffzellen unter Potentialzyklisierung [Bachelor]. Oldenburg: Carl-vonOssietzky Universität Oldenburg; Deutsches Zentrum für Luft- und Raumfahrt Institut für Vernetzte Energiesysteme; 2018.

53. Zielke L, Vierrath S, Moroni R, Mondon A, Zengerle R, Thiele S. Threedimensional morphology of the interface between micro porous layer and catalyst layer in a polymer electrolyte membrane fuel cell. RSC Advances. 2016;6(84):807005; https://doi.org/10.1039/C6RA16560E.

54. Halter J, Marone F, Schmidt TJ, Büchi FN. Breaking through the Cracks: On the Mechanism of Phosphoric Acid Migration in High Temperature Polymer Electrolyte Fuel Cells. J Electrochem Soc. 2018;165(14):F1176-F83; https://doi.org/10.1149/2.0501814jes.

55. Berg P, Kulikovsky AA. A model for a crack or a delaminated region in a PEM fuel cell anode: analytical solutions. Electrochim Acta. 2015;174:424-9; https://doi.org/10.1016/j.electacta.2015.05.189.

56. Froning D, Maier W, Groß J, Arlt T, Manke I, Lehnert W. Evaluation of structural changes of HT-PEFC electrodes from in-situ synchrotron X-ray radiographs. Int J Hydrogen Energy. 2014;39(17):9447-56; https://doi.org/10.1016/j.ijhydene.2014.04.059.

57. Schonvogel D, Rastedt M, Wagner P, Wark M, Dyck A. Impact of Accelerated Stress Tests on High Temperature PEMFC Degradation. Fuel Cells. 2016. 16(4): 480-489; https://doi.org/10.1002/fuce.201500160.

58. Søndergaard T, Cleemann LN, Becker H, Aili D, Steenberg T, Hjuler HA, Seerup L, Li Q, Jensen JO. Long-term durability of HT-PEM fuel cells based on thermally cross-linked polybenzimidazole. J Power Sources. 2017. 342(Supplement C): 570-578; https://doi.org/10.1016/j.jpowsour.2016.12.075.

59. Zana A, Speder J, Roefzaad M, Altmann L, Bäumer M, Arenz M. Probing Degradation by IL-TEM: The Influence of Stress Test Conditions on the Degradation Mechanism. J. Electrochem. Soc. 2013. 160(6):F608-F615; https://doi.org/10.1149/2.078306jes. 
60. Normile SJ, Zenyuk IV. Imaging ionomer in fuel cell catalyst layers with synchrotron nano transmission x-ray microscopy. Solid State Ionics. 2019;335:38-46; https://doi.org/10.1016/j.ssi.2019.02.017.

61. Brus G, Miyoshi K, Iwai H, Saito M, Yoshida H. Change of an anode's microstructure morphology during the fuel starvation of an anode-supported solid oxide fuel cell. Int J Hydrogen Energy. 2015;40(21):6927-34;

https://doi.org/10.1016/j.jijhydene.2015.03.143. 